\title{
BENCHMARKING OF TWO SYSTEMS FOR TRANSMISSION OF MOTION FOR A DOUBLE ACTION STIRLING ENGINE
}

\author{
R. B. e Paula, ABSTRACT \\ P. D. Antunes, \\ P. O. Souza, \\ In a four-piston Stirling engine, Siemens configuration, the displacement of \\ and M. M. V. Leme \\ the pistons is governed by the motion transmission element, which converts \\ the reciprocating motion of pistons into rotary motion. This study aimed to \\ evaluate the influence of the geometry of the transmission element in the \\ mechanical efficiency of a Stirling engine. Analyses were performed using a \\ mathematical computer simulation that uses the geometric and operating data \\ Universidade Federal de Itajubá \\ Departamento de Engenharia Mecânica \\ Bairro Pinheirinho \\ CEP. 37500-903, Itajubá, Minas Gerais, Brasil \\ Received: July 18, 2012 \\ Revised: June 08, 2013 \\ Accepted: June 10, 2013 \\ Keywords: theoretical assessment, stirling engines, transmission mechanisms \\ of motion, simulation.
}

\section{NOMENCLATURE}

AISI American Iron and Steel Institute

AZ Arizona

MW mega Watt

$P \quad$ Mechanical power output, W

$p_{a} \quad$ Internal pressure [MPa]

\section{Greek symbols}

$\Delta p_{a}$ Pressure variation $[\mathrm{MPa}]$

$\Delta V_{a}$ Volume variation [cc]

\section{INTRODUCTION}

With the expansion in clean energy market, to a great extent of research is being conducted to mature alternative technologies for renewable energy conversion. One such technology is the solar Stirling engine that uses solar radiation as heat source using a thermodynamic cycle to convert thermal energy into mechanical shaft power. Demonstration units have reached operational success, achieving the world's highest-to-grid sun energy conversion efficiency (Stirling Energy Systems, 2008).

The first large-scale solar farm using dishStirling technology, rated at $1.5 \mathrm{MW}$, came online in
January 2010 in Peoria, AZ, and its related installations, with several hundred megawatts, are in the planning stages (Tessera Solar, 2010).

The solar Stirling engine ST-15 Fig. 1 was developed by the Spanish company Ingenieria SL Sostenible Cadiz, located in Barcelona, devoted to projects such as sustainable electrical generation turbines, Stirling engines, air conditioning of buildings projects, research projects and development of new products.

The ST-15 was designed to generate $18.5 \mathrm{~kW}$ of electric power, of which $3.5 \mathrm{~kW}$ to supply its auxiliary's equipments, such as water pumps, radiator, control system and the solar tracker engines. The working fluid is Helium, and it can operate with compressed air. The configuration of the Stirling engine is a dual-action, or Siemens, four-piston, which gives a slim profile, lightweight which produces little shadow in the mirros parables. The parable of the solar tracker has an area of $75 \mathrm{~m}^{2}$ and was developed by a specialized company in this sector. Engine efficiency varies with solar radiation, reaching $25 \%$ in the period of maximum solar isolation.

Table 1 contains the main technical data for the Stirling engine ST-15.

The principle of operation of the engine is based on the Stirling cycle, where a pressurized gas is compressed by the piston in the bottom of the cooling zone and subsequently the gas is displaced, also with 
the help of the piston to the hot zone, where it absorbs heat and expands producing force on the piston. Due to the transmission mechanism of the force on the pistons (reciprocating rectilinear motion) the movement is converted into torque (rotational motion).

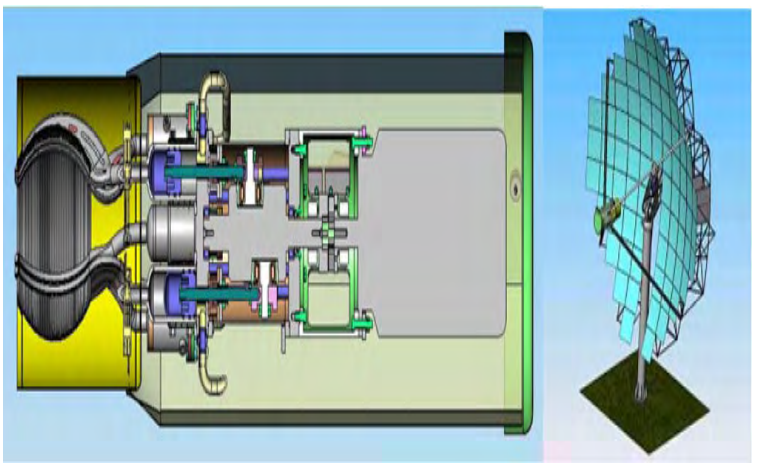

Figure 1. Simplified general scheme for the ST-15 solar Stirling engine.

Currently, there are several types of transmission systems of movement that can be implemented in the fourth piston round distributed Stirling engines, the geometry of Ross-Triebwerks, the combination of the $\mathrm{Z}$ axis (Z-crank) and swash plate (wooble-plate) and mechanism of sliding plate (Swashplate Mechanism). Figure 2 illustrates each of these systems.

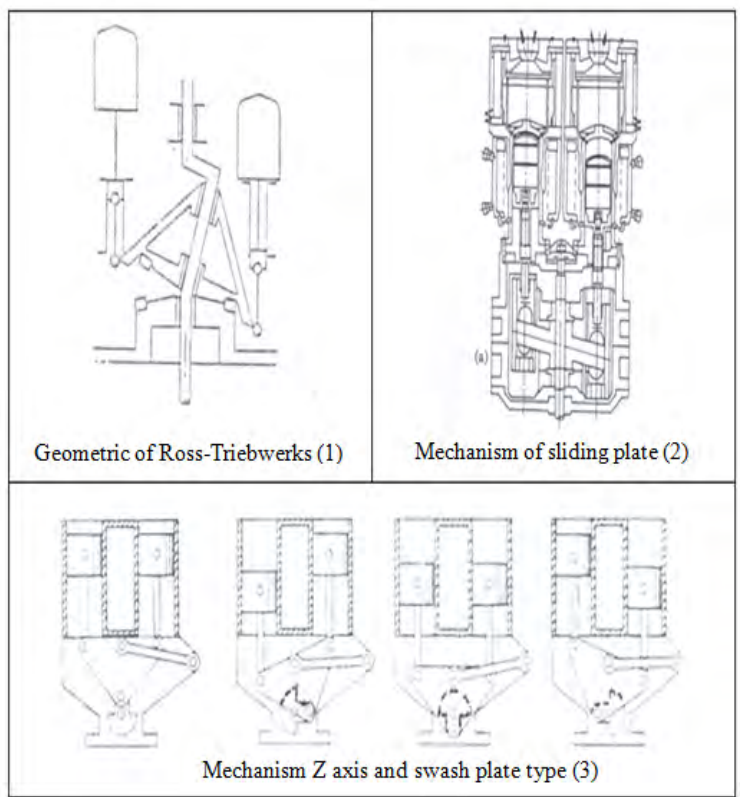

Figure 2. Types of mechanisms of transmission of motion for double-acting Stirling engines (Siemens) (Werdich and Kübler, 2003).

The transmission mechanism of the engine ST15 (Fig. 3) is an axis whose central geometry, the larger one, houses a deep groove whose profile is sinusoidal around the circumference of which the beginning and end of the sinusoid coincide at one point. Within this groove are housed four bearings where the pistons are fixed. When the central axis starts its rotational movement, the bearings of the pistons cross the sinusoidal profile, resulting in reciprocating and straight motion toward the axis.

In this context, this study aimed to evaluate the influence of geometry element transmission of rotary motion into the mechanical efficiency of a solar Stirling engine ST-15.

Table 1. Technical data of ST-15 solar Stirling engine.

\begin{tabular}{|c|c|}
\hline \multicolumn{2}{|l|}{ Engine } \\
\hline Piston diameter & $90 \mathrm{~mm}$ \\
\hline Piston stroke & $65 \mathrm{~mm}$ \\
\hline Number of pistons & 4 \\
\hline Working fluid & $\begin{array}{l}\text { Helium } \\
\text { or Air }\end{array}$ \\
\hline Internal pressure & 55 bar \\
\hline $\begin{array}{l}\text { Final separation at the top of piston } \\
\text { (expansion) }\end{array}$ & $1 \mathrm{~mm}$ \\
\hline $\begin{array}{l}\text { Final separation at the top of piston } \\
\text { (compression) }\end{array}$ & $4 \mathrm{~mm}$ \\
\hline $\begin{array}{l}\text { Phase difference between expansion and } \\
\text { compression pistons }\end{array}$ & $90^{\circ}$ \\
\hline $\begin{array}{l}\text { Working gas temperature inside the } \\
\text { heater }\end{array}$ & $650^{\circ} \mathrm{C}$ \\
\hline $\begin{array}{l}\text { Working gas temperature inside the } \\
\text { cooler }\end{array}$ & $70^{\circ} \mathrm{C}$ \\
\hline Absolute mean pressure & $58 \mathrm{bar}$ \\
\hline Maximum speed & $\begin{array}{c}1020 \\
\mathrm{rpm}\end{array}$ \\
\hline \multicolumn{2}{|c|}{ Data from the hot heat exchanger (heater) } \\
\hline Material & $\begin{array}{l}\text { AISI } \\
316 \mathrm{~L}\end{array}$ \\
\hline Quantity of tubes & 48 \\
\hline Internal diameter & $4 \mathrm{~mm}$ \\
\hline Length & $250 \mathrm{~mm}$ \\
\hline \multicolumn{2}{|c|}{ Data from the hot heat exchanger (cooler) } \\
\hline Material AISI-316 L & $\begin{array}{l}\text { AISI } \\
316 \mathrm{~L}\end{array}$ \\
\hline Quantity of tubes & 60 \\
\hline Internal diameter & $4 \mathrm{~mm}$ \\
\hline Length & $138 \mathrm{~mm}$ \\
\hline \multicolumn{2}{|l|}{ Regenerator } \\
\hline Quantity 184 & 184 \\
\hline Material AISI-316 L & $\begin{array}{l}\text { AISI } \\
\text { 316L }\end{array}$ \\
\hline Regenerator diameter & $90 \mathrm{~mm}$ \\
\hline Wire diameter & $0.1 \mathrm{~mm}$ \\
\hline Length & $37 \mathrm{~mm}$ \\
\hline Porosity & 0.685 \\
\hline
\end{tabular}

\section{EXPERIMENTS}

To simulate the engine, a mathematical model of isothermal second order was implemented in Excel software, from the program prepared by Martini 
(Martini, 1983). This mathematical model is relatively simple and requires low computational consumption, particularly useful for the optimization of engines since the beginning of its design. Initially, a brief computational procedure determines the basic power and heat input. The basic power then is degraded by various identifiable losses, and more heat input is added according to the known thermal losses in real engines of this type. Consequently, an estimation is made as to the actual power output and heat input actually required.

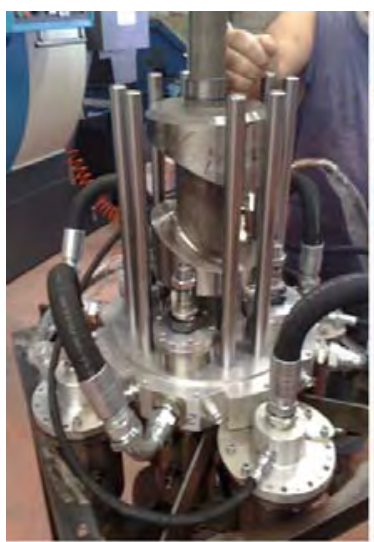

a)

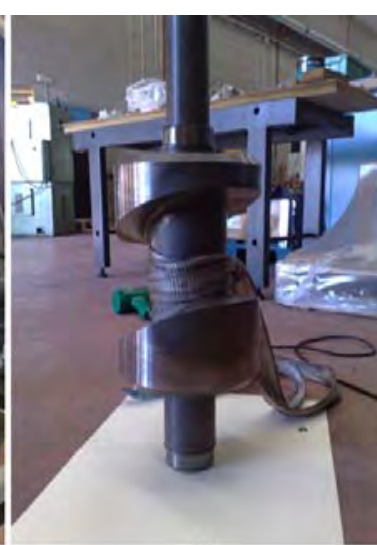

b)
Figure 3. Photos of the shaft of the transmission mechanism. a) shaft supported on the structure of the medial motor. b) insulated shaft.

The Schmidt cycle, well known for these engines, also called the Stirling cycle is the used to simulate adiabatic second order thermodynamic cycle, as mentioned before. The thermodynamic definition of a Stirling cycle is an isothermal compression and expansion with a heating and cooling at constant volume.

The data used for the execution of the simulation are presented in Tab. 1. It is also necessary to know other data as the temperatures of hot and cold heat exchangers, environmental conditions, consumption of auxiliary equipment and electromechanical equation of motion of the pistons usually lagged $90^{\circ}$ between them.

For comparison of the two transmission mechanisms of movement, only the equation of the sinusoidal profile is changed, keeping all other variables and equations fixed.

During the simulation, for each $1^{\circ}$ of axis rotation the pistons positions were calculated in relation to a reference as well as their velocities, accelerations, internal pressure for each of the four chambers formed by the upper side of a piston and the bottom side of the next piston, the temperatures of the working fluid in each zone of the chamber (with 5 zones: hot heat exchanger, a channel of connection between the hot exchanger and the regenerator, regenerator, pipe between the regenerator and the cold exchanger, cold heat exchanger) and other data relating to system efficiency and electric power generated. The mechanical power was calculated by summation of each delta pressure multiplied by delta volume divided by 2 for each of the angles of the axis, as follows:

$$
P=\sum_{1}^{360}\left(\frac{\Delta p_{a} \cdot \Delta V_{a}}{2}\right)
$$

Where $a$ is the angle that ranges from $1^{\circ}$ to $360^{\circ}$.

Since the delta volume depends on the profile of the transmission mechanism equation, it was possible to determine and compare the performance of each of these mechanisms in relation to mechanical power. At the same time, we also can compute the velocities and accelerations of the piston based on the same equation, because for a same rotational speed the time between an angle plus $1^{\circ}$ is the same between them and so the speed can be calculated as delta offset multiplied by the delta time and acceleration can be calculated as the delta speed by delta time.

\section{RESULTS AND DISCUSSION}

Typically the profile of used is sinusoidal, since the new profile is a modification of the proposed sinusoidal, where the "valleys" and "ridges" of the sinusoid are flatter and steeper slopes. Figure 4 illustrates the difference between the profiles used.

The advantage of using this new profile again based on the principle of engine operation, occurs because the peaks and valleys are flattened and the piston can spends more time in the zones of heating and cooling, resulting in greater heat absorption and heat rejection by the working fluid and therefore more thermal energy is converted into mechanical power.

Figure 5 shows the graph of pressure versus the volume of the Stirling cycle for both cases and can be notice that the inner area, which corresponds to the work produced is higher for the case of modified sinusoidal profile, as predicted theoretically.

As each piston is at a certain point of the profile, each of them will have a different velocity and acceleration between them. This causes oscillations and vibrations in the engine.

Figure 6 graphically shows these oscillations for each profile considered, and additionally shows the oscillations caused by motion transmission mechanism comprising the traditional crank drive.

One can see from the graph that the behavior of the oscillations resulting from the use of profile sinusoidal and the crank drive system are well behaved and follow a sinusoidal pattern of period and fixed frequencies proportional to the rotation speed of the shaft. For these cases a balance is sufficient to annul the vibrations caused by the accelerations of the pistons. 


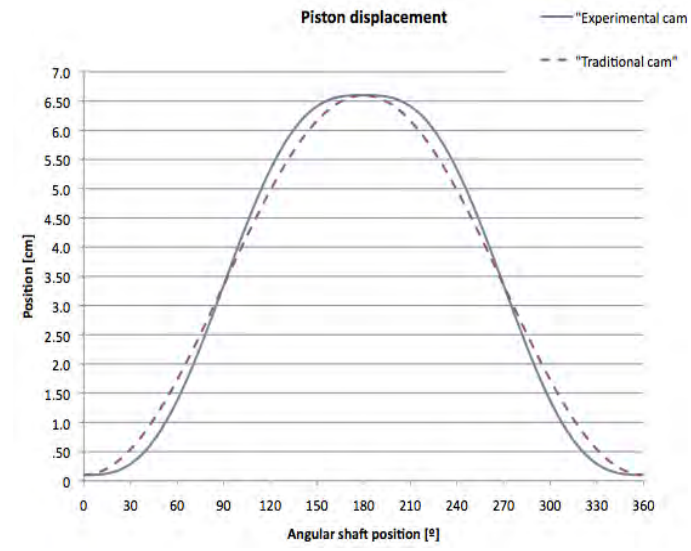

Figure 4. Difference between the sinusoidal profiles. In red, the most commonly used profile. In blue the profile slightly modified.

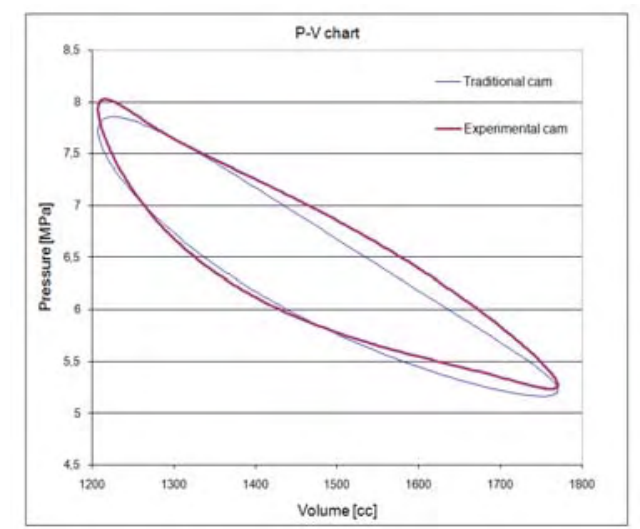

Figure 5. Chart Pressure x Volume. In blue the curve corresponding to the sinusoidal profile. Red curve corresponds to the profile slightly modified.

As for the case of the modified profile, it is notable that a different behavior is presented, with the same period, but with harmonics frequencies. These harmonics cause the inadequate share balance system, making necessary the utilization of a specific vibration damping system, in this case, specifically designed to cancel this kind of fluctuation.

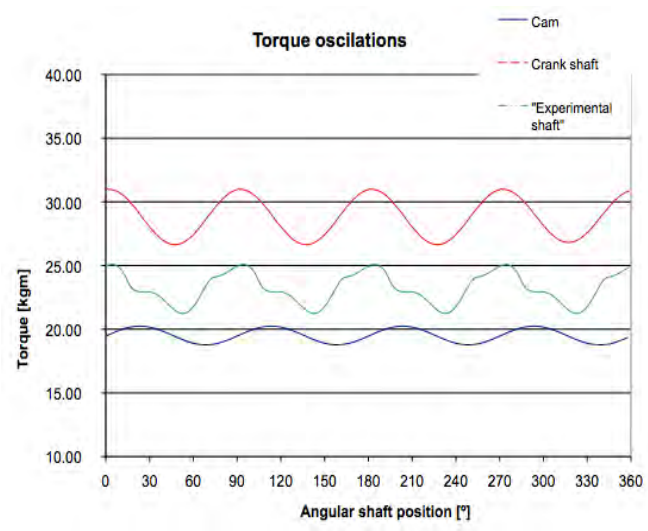

Figure 6. Oscillations caused by different types of transmission mechanisms of movement. Blue sinusoidal profile, the modified profile in green and red traditional crank drive.

\section{CONCLUSIONS}

Through computer simulations, it was found that using the sinusoidal transmission mechanism, the Stirling engine ST-15 produced under the employed conditions of temperature and pressure, at a net power output shaft of 5,962 kW.

When using the new profile the power net on the output shaft was $6,057 \mathrm{~kW}$, resulting in an increase of $1.59 \%$ on mechanical power.

Despite gains in the mechanical power, it was found that when employing the new sinusoidal profile, the strong accelerations and decelerations, interspersed by periods of inactivity inertial sometimes cause a strong vibration in the motor assembly with a complex pattern, requiring an astute system with counterweights to negate this effect. That situation didn't occur with the mechanism with sinusoidal profile, which, although has also present vibration, but with a more favorable implementation of a balance system that would easily nullify the vibrations.

Besides the increase in mechanical power, this gain don't make up for the use of a high complex mechanism of balance, and the sinusoidal profile is indicated for use by the fourth piston Stirling engine configuration Siemens.

\section{ACKNOWLEDGEMENTS}

The authors thanks to Ingenieria Sostenible Cadiz S. L. for technical support.

\section{REFERENCES}

Martini, W. R., 1983, Stirling Engine Design Manual, Martini Engeneering, $2^{\circ}$ Edition.

Stirling Energy Systems, 2008, Sandia, Stirling Energy Systems set new World Record for Solar-toGrid Conversion Efficiency, Feb. 2008.

Tessera Solar, 2010, Tessera Solar and Stirling Energy Systems Unveil World's First Commercial Scale Suncatcher TM Plant, Maricopa Solar, with Utility Partner Salt River Project, Jan. 2010.

Werdich, M., Kübler, K., 2003, StirlingMascinen. Grundlagen Technik Anwendungen, 2003.

Knox, E. M., and Cowling, M. J., 2000, Durability Aspects of Adhesively Bonded Thick Adherend Lap Shear Joints, International Journal of Adhesion and Adhesives, Vol. 20, pp. 323-331.

Loh, W. K., Crocombe, A. D., Abdel, M. M., Ahab, W., and Ashcroft, I. A., 2002, Environmental Degradation of the Interfacial Fracture Energy in an Adhesively Bonded Joint, Engineering Fracture Mechanics, Vol. 69, pp. 2113-2128.

Mathews, F. L., and Hollaway, L. C., 1999, Handbook of Polymer Composites for Engineers Woodhead Publishing Limited.

Neves, P. J. C., Silva, L. F. M, and Adams, R. D, 2009, Analytical Models of Adhesively Bonded 
Joints-Part II: Comparative Study, International Journal of Adhesion and Adhesives, Vol. 29, pp. 331341.

Silva, A. H. M. F. T., 2010, Critério de Falha para Juntas Coladas Submetidas a Carregamentos Complexos, Doctoral Thesis, Universidade Federal Fluminense, Niteroi, RJ. (in Portuguese)

Silva, L. F. M. , Carbas, R. J. C., Critchlow, G. W., Figueiredo, M. A. V, and Brown, K., 2009, Effect of Material, Geometry, Surface Treatment and Environment on the Shear Strength of Single Lap Joints, International Journal of Adhesion and Adhesives, Vol. 29, pp. 621-632.

Zhang, Y., Vassilopoulos, P. A., and Keller, T.,2010, Effects of Low and High Temperatures on Tensile Behavior of Adhesively-Bonded GFRP Joints, Composite Structures, Vol. 92, No. 7, pp. 1631-1639. 